\title{
ERRATUM
}

Armin J. Becker · Stefan Ückert $\cdot$ Christian G. Stief Michael C. Truss · Uwe Hartmann · Udo Jonas

\section{Systemic and cavernous plasma levels of endothelin (1-21) during different penile conditions in healthy males and patients with erectile dysfunction}

Published online: 20 December 2001

(C) Springer-Verlag 2001

The article by AJ Becker et al. in World Journal of Urology (2001) 19: 267-271 was inadvertently published again with a slightly different layout on page $371-376$ of the same volume. For this reason have these pages been removed from LINK.

We apologize to Dr. Becker and his colleagues and to our readers for this error.

\footnotetext{
A.J. Becker · S. Ückert · C.G. Stief $(\bowtie) \cdot$ M.C. Truss · U. Jonas Hannover Medical School,

Department of Urology,

Carl-Neuberg-Strasse 1,

30625 Hannover, Germany

E-mail: stief.christian@mh-hannover.de

Tel.: + 49-511-5323437

Fax: + 49-511-5328437

U. Hartmann

Hannover Medical School,

Department of Psychological Medicine,

30625 Hannover, Germany
} 